\title{
4
}

\section{A Different Way to Approach the Future: Using Chaos Theory to Improve Planning}

\author{
Marc Cutright \\ Ohio University
}

Strategic planning is a good idea that gets a bad name from dubious efforts carrying the title. Much of this rap comes from half-hearted exercises, but some of it comes from efforts that founder due to faulty or limited conceptions of how the future "works." Chaos theory is an alternative approach and metaphor with potential to let us see the future and its dynamics in new ways. Cognizance of chaos's nature and underlying structure might help us do planning in new, nonintuitive, and more successful ways.

\section{Introduction}

Proponents of strategic planning in higher education were perhaps disheartened to see the process included among the management and leadership tools discounted and even ridiculed by noted scholar Robert Birnbaum in his 2001 book, Management Fads in Higher Education: Where They Came From, What They Do, Why They Fail. The approach to active leadership in shaping an institution's future was considered just another suit borrowed from the world of business, fit poorly to the world of academic endeavor.

Those of us with some years of experience in higher education, either in administration or faculty life, have no doubt seen the concept poorly executed, the description strategic attached to ideas of suspect merit. The word carries connotations of cunning, vision, lean-and-meanness, a crystalline contrast to the classic "organized anarchy" and "ambiguity of purpose" (Cohen \& March, 1974 ) that so often seem to be conditions of our daily lives and interactions on 
campus. Strategic is a term that we've allowed self-appointed change agents to seize and attach to their efforts without challenge, as if they were granted authorization to self-declare their work "excellent."

Indeed, I came to the study of strategic planning not out of positive, revelational experience that I felt compelled to share with the world, but from discomfort with and vexation about the strategic planning processes into which I'd been drawn or had witnessed at close range at a number of institutions. I recall one university system "strategic" planning process that involved only a few trustees and high-level administrators, and no faculty representation. The group delivered their final product in a short series of closed-circuit video presentations from a central location, open locally to anyone on campus who wanted to have "input." The meetings were poorly attended, and at least at my location, no one offered reaction or questions. Perhaps the plan was perfectly conceived and delivered. Perhaps people felt no connection between it and their lives. I can't recall that it was ever again referenced to support the deployment of resources or the pursuit of goals.

In another instance, I was involved with a small group of administrators in updating a five-year strategic plan for the campus. In the plan's fourth year, it was dusted off and examined point by point. It seemed a bit distant from the realities of its conception, but we used it as the template to conceptualize our future. When it came to the issue of percentage of minority enrollment for the campus, we noted that the plan called for us to be at $13 \%$ AfricanAmerican representation in the plan's fifth year, the one coming up. A new and high-ranking administrator felt that such a figure was unambitious, and was successful in setting a goal for the upcoming year of $15 \%$. That we were then at $11 \%$ African-American enrollment, and that the target year of enrollment increase would welcome the incoming class in six weeks from the date of the meeting, was of little concern or worry. We were, after all, writing poetry, not policy that would affect daily lives and actions.

Yet there are shining examples of strategic planning well executed, instances of colleges seizing and directing their futures, cases that lead us to believe that our institutions need not be corked bottles bobbing on the sea, but that they can be fairly sleek ships capable of direction and purpose. George Keller (2004) describes Elon University's emergence, through strategic planning and execution, from middling reputation and precarious finances to preeminence as a liberal arts institution. I researched and described, with several others, 13 institutions, from community colleges to research universities, that have established preeminent programs for the first year of college, primarily through deliberate institutional will, planning, follow-through, and continuous improvement (Barefoot et al., 2005). 


\section{Two Divergent Approaches}

Strategic planning efforts can range from the superficial and ineffective, to the substantial and transformative. I have come to believe that these extremes might be characterized as the "Theory X" and the "Theory $Y$ " of strategic planning, after and with apologies to McGregor's (1960) description of oppositional approaches to and theories of human motivation in organizations. Theory $\mathrm{X}$ of strategic planning might be characterized as follows:

- Planning is mandated by, and executed to meet at a minimal level, the policies of external agencies such as governing boards, state legislatures, or accrediting agencies.

- Planning is periodic, episodic, and discontinuous.

- Plans are crafted from sketchy and limited information, almost all of it statistical. Only persons of a certain status have meaningful opportunities for input, and information is gathered along conventional chains of command.

- The planning process avoids conflict, particularly as it might question the institution's core purposes and reasons to exist.

- Planning is directed and controlled to a very high degree by the institution's chief executive officer.

- Planning assumes that a sufficient amount of information on current circumstances will yield an accurate prediction of the future.

- Plans are highly detailed, project far into the future, and depend on a deliberate sequence of events.

- Budgets and plans are linked in one of two ways: not in the least, or in rigid lock, with no room for contingencies.

Theory $\mathrm{Y}$, in contrast, might have these characteristics:

- Planning is driven by the institution's desire to identify and develop its potential.

- Planning is continuous.

- Planning is open to a broad range of opinion, information, aspiration, and argument throughout the broadly defined constituency of the institution. 
- Planning is focused on the priority of articulating the institution's core purposes and priorities.

- Planning is energized and legitimized, but only generally directed, by the chief executive officer.

- Planning points a direction, but is not overly detailed and hard to remember.

- Planning allows for the pursuit of opportunities that may arise in the future but are not currently foreseen.

Theory $\mathrm{Y}$ has consistency with some of the most current, progressive, and successful practices of higher education planning. These would include Peterson's (1997) idea of contextual planning, which he proposes as more proactive and holistic than conventional planning in higher education; Neumann and Larson's (1997) emphasis on widely distributed leadership that rejects conventional linear leadership and instead draws upon existing institutional patterns and values; and Chaffee and Jacobson's (1997) foci on the criticality of identifying subtle organizational imperatives, of building a shared vision through trust and mutual understanding, and of opening the planning process to seeming, initial disorder.

Some of the differences between Theory $\mathrm{X}$ and Theory $\mathrm{Y}$ are rooted in sincerity in the planning process. Minimal compliance with external mandates, for example, is a practice that even its practitioners will concede is not a reasonable route to transformative change. Many of the differences are due, however, to very different world views, very contrasting preconceptions about the nature of our organizations, the means by which things are accomplished, and how the future unfolds. Theory $\mathrm{X}$ can come, in very large part, from the conception of organizations, including colleges and universities, as mechanical in nature.

The position espoused in this chapter is that metaphor, our borrowed constructs of sense-making in our organizations, is essential to how we view, explicitly and implicitly, our roles in these organizations and how things get done. Further, an argument is put forth that our dominant metaphor, that of our organizations as mechanical devices-machines-must be explicitly recognized and rather forcefully displaced if we are to be liberated from its limitations. Finally, an extended metaphor for organizations based on chaos theory is put forward, in the hope that it both provides a different way to conceptualize strategic change in the college or university and creates a "tent" under which some progressive and realistic planning concepts can be gathered. 


\section{Why Metaphor?}

A distant relative by marriage some years ago suffered a massive and catastrophic stroke. His chances of surviving the night, let alone beyond, were put at $5 \%$. But his resolve to live, the miracles of medical science, and perhaps miracles beyond human invention, brought him back from the brink of death. He began a slow and difficult recovery.

In the days and weeks of hospitalization to come, the victim would attempt to engage his visitors in "conversations" that seemed scattered and sometimes nonsensical. Eventually, in brief and tiring efforts, he tried to relate what had happened to him, what he had experienced. A description recurred: "Hard disk crash. Data lost. Can't reboot. Have to reboot."

Maybe that means nothing. I am neither psychologist nor neurologist, not that they have an uncontestable grasp on how the brain works. But it seems to me that while my relative had lost much of his ability to conceive and express what had happened to his mind and his efforts to heal it, the metaphor of his mind and its processes as a computer, a machine, was alive and explicit.

The importance of metaphor in our conceptions of our selves and our environments should not be underestimated or considered a mere poetic device. Since at least Plato's allegory of the cave, we have a record of the significant role played by metaphor in our descriptions of the world around us. Linguist George Lakoff and philosopher Mark Johnson (1980), in their collaborative Metaphors We Live By, assert that metaphor is inseparable from conceptualizations of the world and our organization of it:

[M]etaphor is pervasive in everyday life, not just in language but in thought and action. Our ordinary conceptual system, in terms of which we both think and act, is fundamentally metaphorical in nature. (p. 1)

Further,

We draw inferences, set goals, make commitments, and execute plans, all on the basis of how we in part structure our experience, consciously and unconsciously, by means of metaphor. (p. 158)

A metaphor for an organization and its processes, then, has utility for shaping our very conceptions of the organization. As Gareth Morgan (1986) wrote in the first edition of his book, Images of Organization,

Metaphor is often just regarded as a device for embellishing discourse, but its significance is much greater than this. For the use of metaphor 
implies a way of thinking and a way of seeing that pervade how we understand our world generally.... [M] etaphor exerts a formative influence on science, on our language and on how we think, as well as how we express ourselves on a day-to-day basis. (pp. 12-13)

\section{Metaphor and Organizational Life}

Recent decades particularly have seen the emergence of key metaphors for organizational life in higher education. Among the most prominent of these are the garbage can and organized anarchy models of institutional choice and decision making (Cohen \& March, 1974; Cohen, March, \& Olsen, 1972). Weick (1976) described educational systems, including universities, as "loosely coupled systems," reminiscent of Cohen, March, and Olsen's "uncoupling of problems and choices." Orton and Weick (1990) would return to the idea that loose coupling "baffled and angered" (Weick, 1976) administrators in their efforts to plan and otherwise direct colleges and universities. Loose coupling, rather than being perceived as a means by which institutions could be more sensitive to environmental changes, was instead widely perceived as a diametrically oppositional concept to management, and a source of resistance to change (Orton \& Weick, 1990). Indeed, George Keller (1983), the most prominent proponent of, and author on, strategic planning, considered both organized anarchy and loose couplings to be crises, not elements of flexibility and adaptability, in confronting a new era of harsh competition for resources.

If metaphor is central to our organization of the world, and if many in higher education would eschew metaphors such as those noted above, then what is, exactly, the operative metaphor, the implicit one, if not the explicit one?

Gareth Morgan (1997) is among those who say that the dominant organizational metaphor for our organizations is that of the machine. He notes that this metaphor can be useful, when the environment is stable, when the product is uniform, and when the "human 'machine' parts are compliant and behave as they have been designed to do" (p. 27). The description seems consistent with Frederick Taylor's (1911) scientific management of the early 20th century. The model has the characteristics of a machine, in that, consistent with Newtonian mechanics, there's a predictability and replicability to cause and effect; there's a hierarchy of actions and controls; and elements of the machine can be isolated and tinkered with.

Margaret Wheatley, in her 1992 book Leadership and the New Science, holds that we have focused our organizational energies on 
Structure and organizational design, on gathering numerical data. ... We believed that we could study the parts ... to arrive at knowledge of the whole. We have reduced and described and separated things into cause and effect, and drawn the world into lines and boxes. (pp. 27-28)

Oxford physicist and philosopher of science Danah Zohar (1997) sees an organizational world of "Newtonian organizations... that thrive on certainty and predictability.... Power emanates from the top.... [Such organizations] are managed as though the part organizes the whole." The emphasis on control and command "isolates these organizations from their environments" (p. 5).

Lincoln and Guba (1985) are among those who argue that such metaphors extend to and dominate our views of educational organizations. Higher education planners and authors Michael G. Dolence and Donald M. Norris (1995) describe both the processes and organizations of higher education as being of "classic, late Industrial Age design," a "factory model" characterized by "insufficient flexibility" and a fixation on processes rather than outcomes (p. 11).

\section{Why Chaos Theory, and What Is It?}

A Virginia commission, charged in the late 1980s with the development of a master plan or vision for higher education in that state, used chaos theory as an analytical framework. The short definition of chaos theory given in that report serves us well as a beginning point:

A mathematical concept called, somewhat misleadingly, "chaos," holds that at certain points small changes within systems will produce great and unpredictable results.... The mathematics created to conceive... "chaotic" situations is nonlinear: the future does not follow trends established in the past.... What [chaos theory] represents to us is the probability that the future will not be simply a linear extrapolation of the past, that small events happening today will cause new patterns to emerge downstream. (Commission on the University of the 21 st Century, 1989, inside back cover)

Chaos, in the physical sciences, is not the random activity that the term's common use suggests. Chaos theory instead holds that many seemingly random activities and systems in fact show complex, replicated patterns. The behavior of these systems is nonlinear; that is, behavior feeds back upon itself 
and modifies the patterns. Further, predictability of the system's behavior is restricted to a relatively short timeframe.

Chaos theory's roots in science go back more than a century (Ruelle, 1991), but ongoing attention to chaos theory is broadly considered to have begun with the work of meteorologist Edward Lorenz (1993). Working with early 1960s computers and a model of weather development, Lorenz sought to make his computations of prediction more efficient by rounding input conditions measurements, but to a very slight degree, after three decimal places. He expected only slight variations from more pinpoint inputs, but after only a short run of conditions, patterns began to vary substantially from earlier simulations and quickly bore no resemblance at all to earlier predictive calculations. Yet even with these variations, boundaries existed on the system's behaviors, and certain weather patterns recurred. These are conditions that characterize actual weather (Gleick, 1987).

A particularly key principle of chaos theory emerges from this work. Chaotic systems demonstrate extreme sensitivity to initial conditions and extreme sensitivity to influx. This notion is popularly called the butterfly effect, where the flapping of a butterfly's wings in Asia may eventually alter the course of a tornado in Texas (Lorenz, 1993).

The importance of small factors such as these comes through the circumstance that chaotic systems are dependent upon feedback. As opposed to Newtonian concepts that more clearly differentiate between cause and effect and their predictability, feedback is the notion that an effect becomes part of the cause in subsequent iterations of the pattern. Senge (1990) explored this concept as related to organizations in The Fifth Discipline.

What, then, allows chaotic systems to develop any sense of pattern, to stay within boundaries? It is the existence of attractors. Attractors are those elements in a system that have drawing or organizational power. Multiple attractors, even while establishing boundaries on a system, result in less stable, complex patterns, with the attractors acting upon one another. It is the presence of attractors that also gives chaotic systems the quality of self organization, the ability to recreate order and pattern, at least temporarily, despite continuous compensation for internal and external shocks to the system, or turbulence (Parker \& Stacey, 1994).

Chaotic systems demonstrate self-similarity at their various levels. The pattern of the whole can be seen in the part. In natural systems, self-similar structuring, called fractals, is shown in cloud formation, plant structure, landscapes, circulatory systems, wherever chaotic organization appears.

To summarize, a chaotic system is one in which apparently random activity is in fact complexly patterned. Patterns, created by attractors, are 
disrupted and modified by the input of turbulence. Attractors work to keep systems within boundaries. Chaotic systems demonstrate self-similarity, or fractal structuring, at various levels of the system. The infinitely varied interaction of attractors and turbulence make pattern predictability difficult in the near term and impossible over the long term. Despite limited predictability, patterns do emerge and are substantially the creation of system conditions and inputs.

Some individuals working with metaphoric applications of these or similar principles use the term complexity theory rather than chaos theory. This body of work has yet to clearly distinguish itself from chaos theory, and the choice of complexity may be due in large part to the visceral reaction that the word chaos engenders when people fail to separate the theory from the conventional description of randomness. I find useful the distinction made by Edward Lorenz (1993) that complexity is "irregularity in space," and chaos is "irregularity in time" (p. 167). Planning, and organizational foci in general, are overwhelmingly concerned with time, and particularly the future, the single element of this dimension over which we have or seek control.

A word on the limitations of metaphor, including chaos theory, is in order. As Morgan (1997) and many others note, no single metaphor is universally useful or applicable to all circumstances. Metaphors can blind us to circumstances as well as give us new insights. The trick is to become facile in the consideration and application of multiple metaphors.

Metaphors appropriated from physical sciences to social circumstances can be particularly problematic. Social Darwinism comes to mind, with its rationalization of racism, colonialism, and robber-baron capitalism. A contemporary of Isaac Newton's sought to apply the theory of gravity to determination of the veracity of courtroom testimony (Cohen, 1994). Frederick Taylor (1911) and Henri Fayol (1984) were popularizing the application of physical science to social and business arrangements, just as Albert Einstein (1961) was undermining the universality of the Newtonian mechanics upon which scientific management was largely based.

Nonetheless, it is interesting to note that some of the most impassioned calls for the application of chaos theory to social systems have come from prominent scientists and mathematicians who have worked in chaos theory at developmental levels. See, for example, Gell-Mann's (1994) The Quark and the Jaguar, Ruelle's (1991) Chance and Chaos, and Prigogine and Stengers' (1984) Order Out of Chaos. 


\section{Propositions for Strategic Planning}

I put forth 10 propositions about strategic planning that are derived from a coincident consideration of chaos theory and classic and progressive ideas about strategic planning. Together, the propositions form an extended metaphor, a model, which provides a conceptual coherence for an overall approach to the endeavor. Some of the propositions are more obvious, while others might be counterintuitive. Some are bluntly stated; if a dominant metaphor, that of the machine, is to be displaced, it must be pushed aside, summarily if temporarily, to allow for the adequate consideration of this suggested alternative.

These propositions have been examined and largely affirmed against the planning practices and experiences of a number of institutions, particularly Carson-Newman College, a denominational college in Tennessee; the University of Calgary, an institution that would be considered a Carnegie Research University in the American context; Red Deer College, a public two-year college in Alberta; and Blue Ridge Community College in Virginia (Cutright, 1999). Among these four, only Blue Ridge Community College operated from an explicit metaphor of chaos theory (Levin, Lanigan, \& Perkins, 1995; Perkins, Lanigan, Downey, \& Levin, 2001).

Of course, the overwhelming limitation in going into an investigation with an a priori model is that the prejudice will be to confirm it; to a man with a hammer, every problem is a nail. In an effort to minimize this limitation, the preliminary model and draft propositions were made available to all individuals interviewed during the case studies, as were, for the more interested, prior papers and publications that I had produced on this general topic. The propositions were by this process refined for the better, but the overall model emerged largely intact.

Space limitations do not allow for a fuller detailing of these case studies or of the fuller literature foundations of the propositions, except in highlight.

:Proposition 1: The ideal outcome of planning is planning, not a plan.

Dwight Eisenhower was more direct: "Plans are nothing. Planning is everything" (Keller, 1983, p. 99). George Keller (1983) emphasizes the creation of a strategic direction over a fat, detailed document. Academic planners James Morrison, George Wilkinson, and L. Forbes (1999) affirm this viewpoint in their web-published book Common Sense Management for Educational Leaders: "Keep this in mind: The product you are seeking at each step is not a written report. It is a strategic mind-set of the senior leadership, indeed the whole organization." 
The tie to chaos theory is through the butterfly effect. Small, unforeseen changes in the environment mutate it in ways that are largely unpredictable at any level of likelihood. Higher education planning is often marked by plans issued on a time horizon of five, ten, or more years. They are highly sequential, with each step dependent upon the completion, within a specified timeframe, of precedent steps. The plan quickly breaks down. The approach is, one author suggests, somewhat like playing a game of pool by specifying, before the commencement of play, each and every shot through the sinking of the eight ball (Priesmeyer, 1992).

Proposition 2: Planning begins with a distillation of the institution's key values and purposes. These elements are not dictated from above, but discovered from within.

In the paradoxical context of chaos theory, these values and purposes provide a constant source of reference but are always open to challenge and modification. A chaos-theory corollary is that of attractors, those principles that bring order to a general direction for the future, despite turbulence.

The mission statement, so often a kitchen sink of disparate interests and topics, is rarely of much help. Nor is the mission or purpose statement imposed by executive fiat, which ignores the power and reality of existing conditions. As Chaffee and Jacobson (1997) noted, when vision and the institution's resident values go head to head, the result is almost always the same: “Culture 1, Planning 0" (p. 230).

Proposition 3: The widest possible universe of information should be made available to all members of the institution. This universe of information includes ongoing, rich, and current feedback.

Keller's (1983) advancement of the concept of environmental scanning and information gathering as critical to good planning has become widely accepted. Where chaos theory perhaps advances the concept of information gathering and sharing is an emphasis on the importance of feedback. The creation and discussion of plans are themselves a part of the changing environment. Not incorporating this feedback into the planning process separates planning from an evolving environment. While Keller $(1983,1988)$ initially supported the relatively secret Joint Big Decision Committee, he later revised his view to include more open communications to engender trust. Chaffee and Jacobson (1997) held that not only should communications be open and information transparent, but that a full gamut of communication means should be used to assure that all had the best opportunities for knowledge and input. 
Proposition 4: Dissent and conflict are creative, healthy, and real. The absence of conflict is reductionist, illusory, and suspect.

Chaos recognizes and respects the power of turbulence; it is the essence of creativity in chaotic systems. Yet how much of our planning is characterized by a desire to minimize conflict, to subtly suppress dissent, and to reach the earliest possible "consensus"? Premature closure of discussion and debate closes our fuller consideration of alternatives and leaves those of opposing opinion without input options and with an agenda that they will be able to execute, to some degree, in opposition to centrally settled directions. Holton (1995) suggested that conflict is not the problem, but the solution: Conflict "can be cathartic, providing opportunities for revitalization, energizing, and creativity by all in the academy" (p. 94).

\section{: Proposition 5: Linearity doesn't work in strategic planning. It doesn't work in dictation-planning and plans imposed from above-or in collation-planning and plans created solely by the collection of unit information.}

By this point in the argument, the reader may anticipate the argument from chaos theory against top-down, executive-committee-dictated planning: attractors are not identified, feedback is denied, faint recognition of the environment is inevitable, and implementation is crippled by a lack of fractal structure. But less obvious may be the limitations of the opposite impulse, collation. Collation is used here as the collection of individual "plans" by departments or other units, essentially only edited for presentation uniformity in a master document. Chaos theory suggests that this process lacks the connectivity between elements of an organization that would make it a system. Collation without feedback and discussion does not contribute to desirable selforganization that will guide the institution in coherent ways into the future.

\section{:Proposition 6: The institution should budget-fiscally and psychically-for} failure. Pilots are alternate futures. Not all can be realized or succeed.

Experimentation and striking out in new directions are often viewed heroically on the front end, but disparaged on the back side after less-than-favorable results. We should recognize that in planning, as in financial investment, higher returns are made possible by higher risk. The challenge is to improve - not assure - the chances of success. Dolence and Norris (1995) caution that if we wait until "the vision is perfectly clear and risks have vanished, the opportunities will have passed, as well" (p. 4). Morrison et al. (1999) encourage that "you and your [planning] colleagues must be imagina- 
tive, innovative, and willing to take risks," and "that means you are flexible, and not wedded to a set of strategies or action plans that you cannot change."

Chaos theory suggests that the predictive timeline is shorter than is likely the startup and testing times of complex projects. Even though strong data collection and ongoing feedback can result in what might be called wise piloting, some pilots will fail. If we subtly punish or isolate those whose pilots seemed reasonable and which were blessed, but fail, and we quickly distance ourselves from failure rather than examine it for lessons, we discourage the experimentation necessary to discover and create the future. Weick's (1976) articulation of loose coupling saw as one of its benefits the ability to test "mutations and novel solutions" through "many independent sensing mechanisms" (p. 7). Experimentation uses that loose coupling.

This is not to excuse or rationalize foolhardiness in the use of an institution's resources or the discharging of its responsibilities. Failures will be kept to a minimum by careful investigation of opportunities, and ongoing and transparent monitoring of their progress as implemented.

Proposition 7: The considerable expense of time on the front end is an investment. It is recouped, with interest, in the future.

Top-down, stripped-down, feedback-free planning is faster. The appearance of time saving is a false economy. Time and resources will subsequently be wasted trying to sell and implement a plan that is alien to a system's real dynamics. While directive "planning" may appear to be a manifestation of executive vision and an effort for higher education to appear more nimblefooted and businesslike, it is alien to the basic, underlying cultures of higher education and will heighten the chances of failure. In chaos terms, the fractal nature of the organization is ignored, rather than utilized.

Chaffee and Jacobson (1997) tie planning to institutional culture, and they note that changing or redirecting culture takes substantial time, but that the "payoff can be immeasurably large ... in ways that the central administration could never have imagined or planned for" (p. 244). Conversely and "often, in the final analysis, [a] plan cannot be implemented, because key players have not agreed to it" (Innes, 1996, p. 470).

Proposition 8: The executive is nol demoted or minimized. The executive is the most critical shaper and champion of the process. Ultimately, the executive is empowered by the process.

All of this may suggest, without intention, that the college president becomes a figurehead in a planning process informed by chaos theory. Descriptions of 
chaos-related metaphors and management viewpoints have perhaps reinforced this perception. Gareth Morgan (1997) writes, "In complex systems, no one is ever in a position to control or design system operations in a comprehensive way" (p. 272). James Fisher (1994), among the most visible of strong-presidency advocates and occasionally an acerbic commentator, has given voice to the feeling that constituent-involving processes are driven by a "misguided sense of democracy" (p. 62), result in an "unending and totally unproductive morass of committee meetings, faculty meetings, formal and informal dialogues" (p. 62), which leads to paralysis and undistinguished, lowest-common denominator compromise.

I would suggest that the president active in the promotion and advancement of strategic planning may be seen, in the language of chaos theory, as an attractor, a basic element in the formation of a system's patterns. He or she can speed or slow the process, give or deny it legitimacy, seek and celebrate small wins that encourage participation, and provide energy to the process when necessary. Too loose of a hand on the reins, and the president offers insufficient support and guidance. Too tight of a hand, and the process can focus on little else than the president's directives and opinions; think of a pendulum, originally lively, that comes to a stop when drawn to the force and a point of gravity.

Ultimately, the process enhances the president's power, when he or she can tie the widely supported strategic plan to personnel decisions, the allocation of resources, and the commencement or termination of programs.

\section{Proposition 9: That which can be quantified is not to be overvalued, and that which cannot be quantified is not to be discounted.}

Much of the circumstance of unpredictability comes from our inability to discern which small factors in our environment, which butterfly wings, will be absorbed into the dynamics of the system and gain power far out of proportion with the seeming insignificance of their genesis. Originally thought to be most significant in its unemployment benefits, none of the G.I. Bill's massive effects on higher education were identified in advance; perhaps we discounted the power of hopes, dreams, and aspirations. On the other hand, the dominant "fact" of the planning future going into the 1980s was a declining pool of students, which would result in the closing of at least $10 \%$, and perhaps as many as $25 \%$, of American's colleges and universities in the decade then ahead (Keller, 1983). The realized future was an increase in enrollments, and the survival of most institutions on deathwatch.

Albert Einstein put over-reliance upon quantifiable data, and the concurrent under-consideration of such elements as opinion, desires, and ambitions 
into perspective: "Not everything that counts, can be counted; and not everything that can be counted, counts" (Marino, 1995, p. 218).

\section{Proposition 10: The future is a creation, not a prediction.}

This power of agency is the distinguishing context of human chaotic systems. Despite the difficulties of prediction, the certainty of uncertainty, it would be a grave error to take from chaos theory the idea that planning is futile, because the future is unpredictable. Rather, the primary lesson is that the future can be created. Linear planning models stress trend lines and their potential for prediction of the future. Such approaches can project far into the future, but these futures are rarely realized in any recognizable form. Directors of linear planning attempt to execute the future less than they attempt to create it, and they are often wrong.

Peterson (1997) encouraged us to regard the future and the environment as "complex but malleable" (p. 134). But the ability to make long-term changes in the future is dependent upon our willingness, as actors within the university or social system, to make "long-term commitments" and to apply "consistent effort" toward desired ends (p. 153).

Participants in planning processes informed by chaos theory or similar approaches come to realize that the future is an invention; the external and internal environments are strong creative elements in the future, but so are dreams, values, and ambitions. Metaphorically, the flutter of a wing can move not only the breeze but also the system, the college or university, if applied with endurance and in partnership.

\section{Conclusion}

While this chapter has sought to examine progressive and effective strategic planning through the lens of chaos theory, other authors have made provocative and persuasive use of the principles in other higher education contexts. For example, Kathleen E. Allen and Cynthia Cherrey's (2000) Systemic Leadership and Patrick G. Love and Sandra M. Estanek's (2004) Rethinking Student Affairs Practice both draw upon chaos theory and related concepts to advocate for more effective leadership mindsets and practices in student affairs. While these works are directed first and foremost to these practitioners, who often bemoan their lack of formal, directive power in higher education, both books are valuable to anyone in the enterprise who seeks models of leading from the middle and collaborative improvement. 


\section{Note}

Portions of this chapter have previously appeared in the chapters "Introduction: Metaphor, Chaos Theory, and This Book," and "A Chaos Theory Metaphor for Strategic Planning" in M. Cutright (Ed.), Chaos Theory and Higher Education: Leadership, Planning, and Policy (Peter Lang, 2001).

\section{References}

Allen, K. E., \& Cherrey, C. (2000). Systemic leadership: Enriching the meaning of our work. Lanham, MD: University Press of America.

Barefoot, B. O., Gardner, J. N., Cutright, M., Morris, L. V., Schroeder, C. C., Schwartz, S.W., et al. (2005). Achieving and sustaining institutional excellence in the first year of college. San Francisco, CA: Jossey-Bass.

Birnbaum, R. (2001). Management fads in higher education: Where they come from, what they do, why they fail. San Francisco, CA: Jossey-Bass.

Chaffee, E. E., \& Jacobson, S. W. (1997). Creating and changing institutional cultures. In M. W. Peterson, D. D. Dill, \& L. A. Mets (Eds.), Planning and management for a changing environment: $A$ handbook on redesigning postsecondary institutions (pp. 230-245). San Francisco, CA: Jossey-Bass.

Cohen, I. B. (1994). Interactions: Some contacts between the natural sciences and social sciences. Cambridge, MA: MIT Press.

Cohen, M. D., \& March, J. G. (1974). Leadership and ambiguity: The American college president. Boston, MA: Harvard Business School Press.

Cohen, M. D., March, J. G., \& Olsen, J. P. (1972). A garbage can model of organizational choice. Administrative Science Quarterly, 17(1), 1-25.

Commission on the University of the 21st Century. (1989). The case for change. Richmond, VA: Commonwealth of Virginia.

Cutright, M. (1999). A chaos-theory metaphor for strategic planning in higher education: An exploratory study. Unpublished doctoral dissertation, the University of Tennessee, Knoxville. (ERIC Document Reproduction Service No. ED457931)

Cutright, M. (Ed.). (2001). Chaos theory and higher education: Leadership, planning, and policy. New York, NY: Peter Lang.

Dolence, M. G., \& Norris, D. M. (1995). Transforming higher education: A vision for learning in the 21st century. Ann Arbor, MI: Society for College and University Planning. 
Einstein, A. (1961). Relativity: The special and general theory. New York, NY: Crown Publishers.

Fayol, H. (1984). Administration industrielle et générale. Paris, France: Denod.

Fisher, J. L. (1994). Reflections on transformational leadership. Educational Record, $75(3), 54,60-65$.

Gell-Mann, M. (1994). The quark and the jaguar: Adventures in the simple and the complex. New York, NY: Henry Hoit and Company.

Gleick, J. (1987). Chaos: Making a new science. New York, NY: Penguin.

Holton, S. A. (1995). Where do we go from here? New Directions for Higher Education, 92, 91-95.

Innes, J. (1996). Planning through consensus building: A new view of the comprehensive planning ideal. Journal of the American Planning Association, 62(4), $460-472$.

Keller, G. (1983). Academic strategy: The management revolution in American higher education. Baltimore, MD: Johns Hopkins University Press.

Keller, G. (1988, February). Academic strategy: Five years later. AAHE Bulletin, 3-6.

Keller, G. (2004). Transforming a college: The story of a little-known college's strategic climb to national distinction. Baltimore, MD: Johns Hopkins University Press.

Lakoff, G., \& Johnson, M. (1980). Metaphors we live by. Chicago, IL: University of Chicago Press.

Levin, B. H., Lanigan, J. B., \& Perkins, J. R. (1995). Strategic planning in a decentralized environment: The death of linearity. Paper presented at the 24th annual Conference of the Southeastern Association for Community College Research, Asheville, NC.

Lincoln, Y. S., \& Guba, E. G. (1985). Naturalistic inquiry. Newbury Park, CA: Sage.

Lorenz, E. N. (1993). The essence of chaos. Seattle, WA: University of Washington Press.

Love, P. G., \& Estanek, S. M. (2004). Rethinking student affairs practice. San Francisco, CA: Jossey-Bass.

Marino, J. (1995). Clearcutting in the groves of academe. In G. Laxer \& T. Harrison (Eds.), The Trojan Horse: Alberta and the future of Canada (pp. 209-222). Montreal, Canada: Black Rose Books.

McGregor, D. (1960). The human side of enterprise. New York, NY: McGraw-Hill.

Morgan, G. (1986). Images of organization. Newbury Park, CA: Sage. 
Morgan, G. (1997). Images of organization (2nd ed.). Thousand Oaks, CA: Sage.

Morrison, J., Wilkinson, G., \& Forbes, L. (1999). Common sense management for educational leaders. Retrieved May 13, 2005, from http://horizon.unc.edu/projects/CSM/

Neumann, A., \& Larson, R. S. (1997). Enhancing the leadership factor in planning. In M. W. Peterson, D. D. Dill, \& L. A. Mets (Eds.), Planning and management for a changing environment: $A$ handbook on redesigning postsecondary institutions (pp. 191-203). San Francisco, CA: Jossey-Bass.

Orton, J. D., \& Weick, K. E. (1990). Loosely coupled systems: A reconsideration. Academy of Management Review, 15(2), 203-223.

Parker, D., \& Stacey, R. (1994). Chaos, management and economics: The implications of non-linear thinking (Hobart paper 125). London, England: The Institute of Economic Affairs.

Perkins, J. R., Lanigan, J. B., Downey, J. A., \& Levin, B. H. (2001). Chaos theory applied to college planning: A case study in defense of ten propositions. In $\mathrm{M}$. Cutright (Ed.), Chaos theory and higher education: Leadership, planning, and policy (pp. 79-112). New York, NY: Peter Lang.

Peterson, M. W. (1997). Using contextual planning to transform institutions. In M. W. Peterson, D. D. Dill, \& L A. Mets (Eds.), Planning and management for a changing environment: $A$ handbook on redesigning postsecondary institutions (pp. 127-157). San Francisco, CA: Jossey-Bass.

Priesmeyer, H. R. (1992). Organizations and chaos: Defining the methods of nonlinear management. Westport, CT: Quorum Books.

Prigogine, I., \& Stengers, I. (1984). Order out of chaos: Man's new dialogue with nature. New York, NY: Bantam Books.

Ruelle, D. (1991). Chance and chaos. Princeton, NJ: Princeton University Press.

Senge, P. M. (1990). The fifth discipline: The art and practice of the learning organization. New York, NY: Currency Doubleday.

Taylor, F. W. (1911). The principles of scientific management. New York, NY: Harper \& Row.

Weick, K. E. (1976). Educational organizations as loosely coupled systems. Administrative Science Quarterly, 21, 1-19.

Wheatley, M. J. (1992). Leadership and the new science: Learning about organization from an orderly universe. San Francisco, CA: Berrett-Koehler.

Zohar, D. (1997). ReWiring the corporate brain: Using the new science to rethink how we structure and lead organizations. San Francisco, CA: Berrett-Koehler. 